\title{
The Research of Spatial-Temporal Analysis and Decision-Making Assistant System for Disabled Person Affairs Based on Mapworld
}

\author{
Junhui Zhang, Ji Yang, ${ }^{\mathrm{b}, *}$ Yushan Sun ${ }^{\mathrm{c}}$ \\ ${ }^{a}$ National Geomatics Center of China, Beijing, 100830, China \\ ${ }^{\mathrm{b}}$ Open Laboratory of Geo-spatial Information Technology and Application of Guangdong Province, Guangzhou \\ Institute of Geography, Guangzhou, 510070, China \\ ${ }^{c}$ Chinese Academy of Surveying and Mapping, Beijing, 100830, China
}

KEY WORDS: spatial-temporal analysis, decision-making assistant system, disabled person affairs, Mapworld

\begin{abstract}
:
This system combines the Mapworld platform and informationization of disabled person affairs, uses the basic information of disabled person as center frame. Based on the disabled person population database, the affairs management system and the statistical account system, the data were effectively integrated and the united information resource database was built. Though the data analysis and mining, the system provides powerful data support to the decision making, the affairs managing and the public serving. It finally realizes the rationalization, normalization and scientization of disabled person affairs management. It also makes significant contributions to the great-leap-forward development of the informationization of China Disabled Person's Federation.
\end{abstract}

\section{INTRODUCTION}

People who can't ensure the normal life of themselves because of physical or mental defect of congenital or non-congenital are so call disabled people ${ }^{[1]}$. There are 82.96 million disable people in china, who take the proportion of $6.34 \%$ of the total population. These people need the social insurance. Though several years of informationization, China disabled persons' federation has established some systems such as the basic database system, business operational system and statistical account system. But these systems are built and operated independently, the data formats are inconsistent, the coding are not unique, the data are lack of correlation and finally the information isolated islands are formed ${ }^{[2]}$. To solve this problem, this research combined with the current situation of informationization of China disabled persons' federation and proposed a spatial-temporal analysis and decision-making assistant system for disabled person affairs based on Mapworld.

Mapworld is national geo-spatial information service platform of China. It combines all kinds of geographic information resources of different resolution and different map scale all over the world, specially the resources in China. Mapworld is the important component of Digital China. It is a website which contains the most GIS resource in China. It has great significance in providing public service, promoting the informationization process and maintaining the national safety. The statistic data usually has geographic attribution ${ }^{[3]}$. And the combination of statistic data and geographic data can help the research of regulation of statistic data and the sustainable development strategy of society and economy ${ }^{[4]}$. 


\section{BACKGROUND}

\subsection{The characteristic of disabled persons' affair}

The disabled people in China are faced with rejections in the aspect of concept, job hunting, and education and so on. It is necessary to strengthen the vocational education, call for the equality and freedom and enhance legislation for disabled people to make them participate in the normal life equally ${ }^{[5]}$.

The negative attitude and discriminatory behavior to disabled people still exists in China. And this wrong attitude will lead to the isolation of disabled people, and bring more difficulties to their mental state and recovery. Therefore, it is necessary to set right concept to disable people, clear away the indifference and discrimination of the society, adopt the disabled people on the psychological, and consider them as one of the indispensable part. That is the way to protect the disabled people effectively ${ }^{[6]}$.

2.2 Current situation of informationization of China disabled persons' federation

In the recent years, China disabled persons' federation mended the pace of informationization, and made some achievements, which contains the web portals that realized the information publication, the hardware platform include servers, disk array, virtual tape library and network protection products, realized the isolation of Intranet from outside. This hardware platform maintains the operation of information systems of the department. In the aspect of software, the OA (Office Automation System) system expands the use of basic database system, reports system and certification system.

2.3 The necessity of the combination of informationization and Mapworld

The GIS public service platform has significance in the construction of national informationization system. It can promote the developing level of GIS resources ${ }^{[7,8]}$, drive the industrialization development of GIS, improve the standardization of the GIS technology. Finally, the whole GIS industry chain was improved by the system from information acquisition, operation, management and application.

The combination of disabled persons' federation and Mapworld is built on the frame of information of disabled people, and based on the data analyzing and mining from the disabled persons' database system, business operation system and statistic system, as well as the integration of these data. The information resource database was built for data analyzing and mining, it also provided support to the decision making and public information serving.

\section{GENERAL DESIGN OF THE PLATFORM}

\subsection{Data acquisition and integration}

The certification management data, recovery loan project data, sunshine home project data, public benefit education grant data, countryside disabled people information data and statistic data were combined and analyzed in the disabled people information database. These informations were cleaned and transformed, and finally added to the data warehouse.

Meanwhile, the disabled persons' information were collected by GPS devices and labeled on the Mapworld flat form. This realizes the rapid labeling and positioning of disabled persons' information, and provides basis to the application of all kinds of disabled person's information.

\subsection{Design of database}

The business logic model was built based on the demand of business management system. The physical model, which is also called database table relationship model, was built based on logic model. The comprehensive 
database was built based on physical model. Based on this database and the situation of all the information system, the data model was built, and the disabled persons' data market was built. Finally the disabled persons' data warehouse was formed. The logic model of the database is as followed.

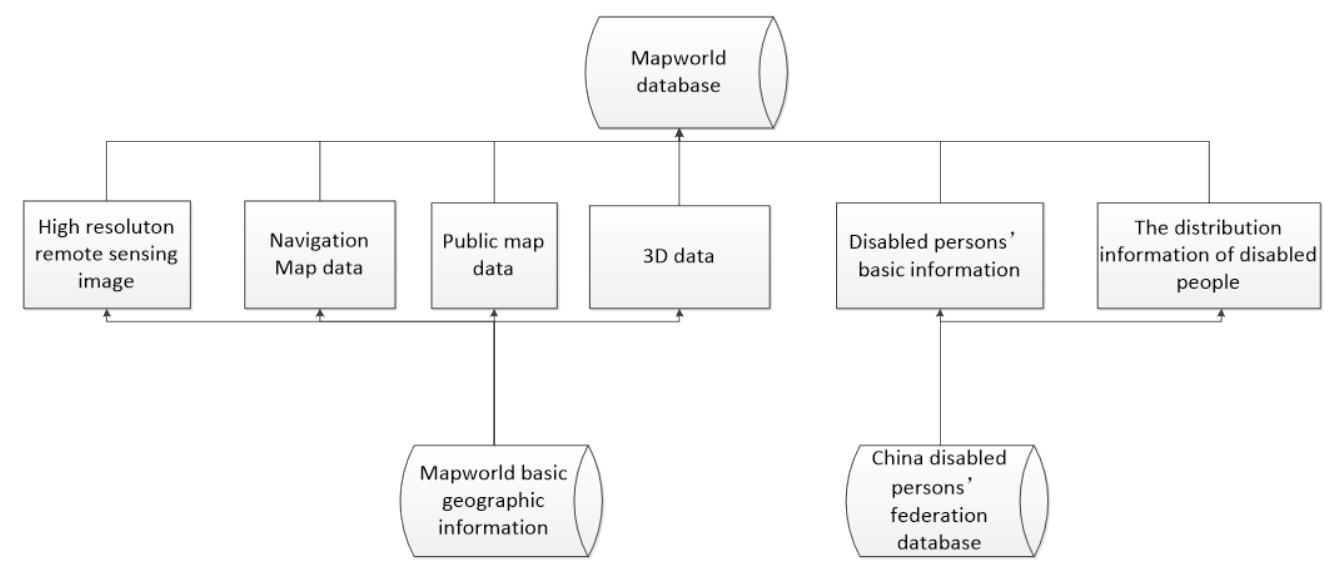

Fig 1: Diagram of Database Logic

The combination of the disabled persons' affair information and the Mapworld basic information realized the overlaying and demonstrating of both spatial data and business data. The accurate positioning of these data provide convenience to check the disabled persons' facilities nearby. The general platform is as bellowed.

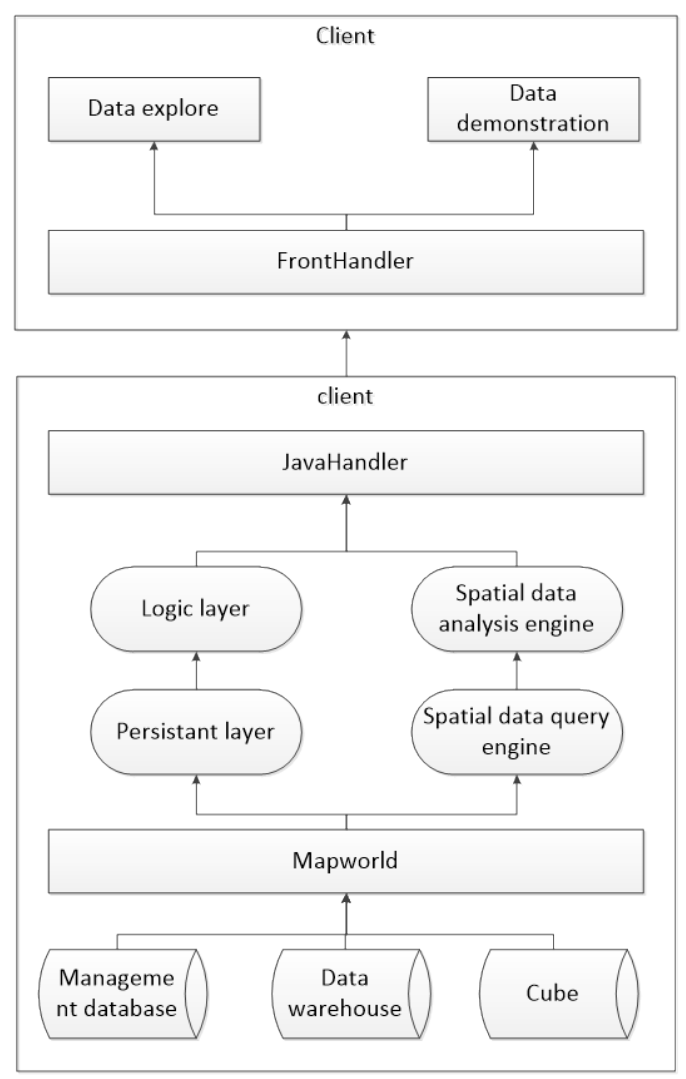

Fig 2: Flow Diagram of System Construction

\section{DESIGN OF PLATFORM FUNCTION}

\subsection{Positon labeling}

\subsubsection{City shifting}

As showed in Figure 3, click the sign of Nanjing in the city list, the position would switch to Nanjing city, and the function of city shifting was realized.

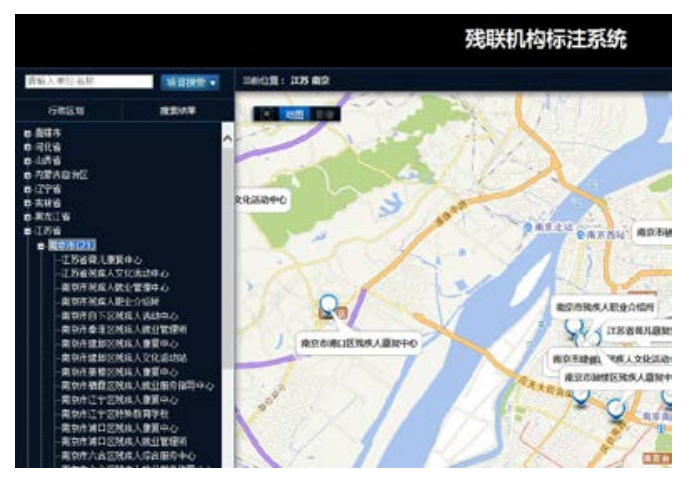

Fig 3: Cities Shifting

\subsubsection{Map shifting}

The platform realized the shifting of vector graph and grid graph as showed in Figure 4 and 5. 


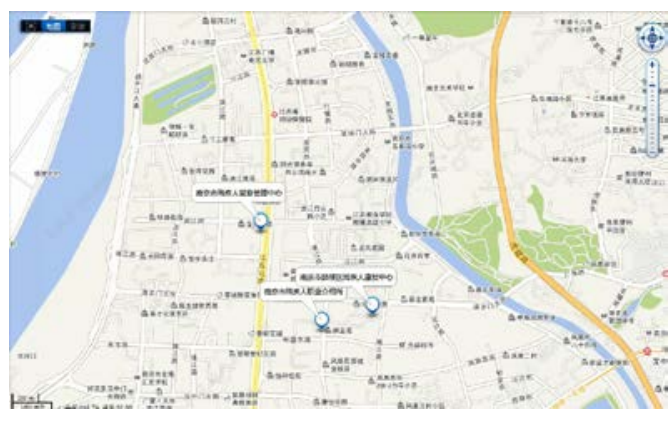

Fig 4: Vector map of map shifting

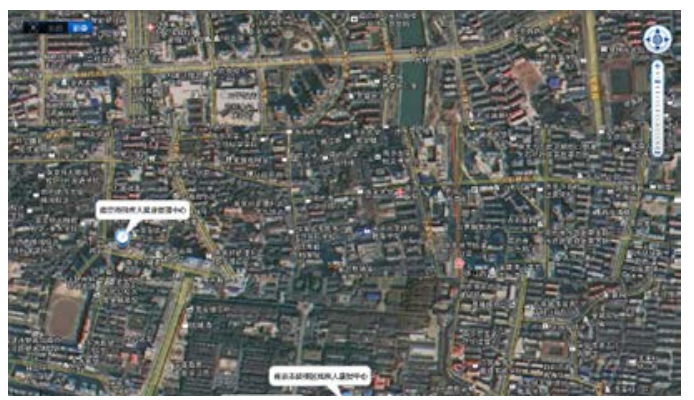

Fig 5: Image map of map shifting

\subsection{Statistic query}

The input query conditions can be basic information such as name, gender and identity number or specific information such as disabled grades, these information can be showed in the proposed platform.

In the interface of Mapworld, the query can be done by the website position and administrative division. The query range can be set to province, city, district and so on to improve query efficiency and accuracy.

\subsection{Design of map service system function}

The map service system function design is showed in figure 6 .

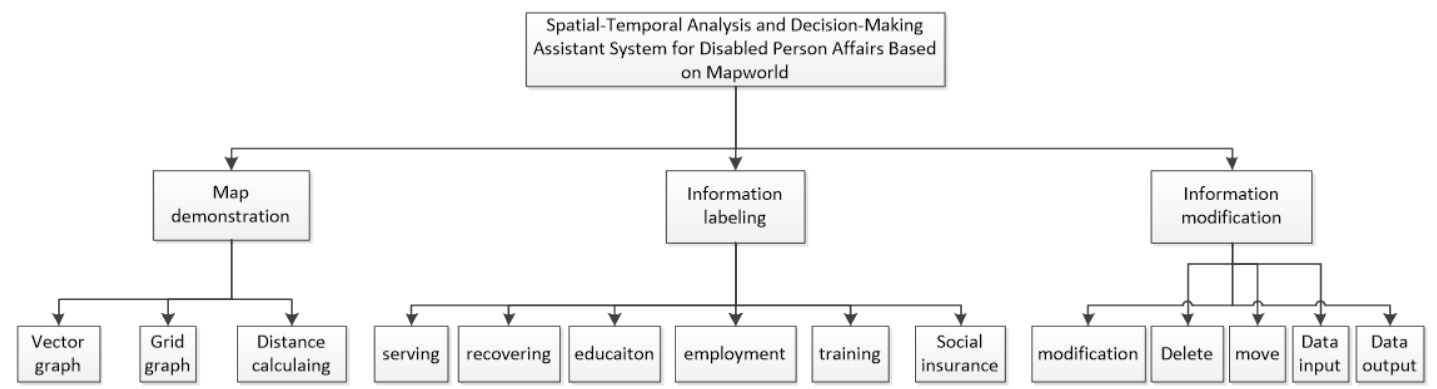

Fig 6: Design of System Function

\section{REALIZATION OF MAPWORLD CHANNEL FOR DISABLED PEOPLE}

Data warehouse is a collection of data which is subject-oriented, integrated and time-dependent. Meanwhile, the data warehouse is support to the decision-making of the manager. The mass data of disabled person management lead to many problems in the aspect of data organization, management and demonstration. These problems made the data warehouse to be necessary. On the basis of data warehouse, the data can be organized and formed as multi-dimensional data, which can be managed and analyzed from different dimension. This is a new solution to mass data management.

\subsection{Partition statistic method}

The statistic data can be formed as different kinds of graphics by district as units. These graphics includes point, line and area. The combination of shape, orientation, size, color and brightness formed all kinds of graphic types. The length, area and volume of the graphics are in direct proportion to the numbers.

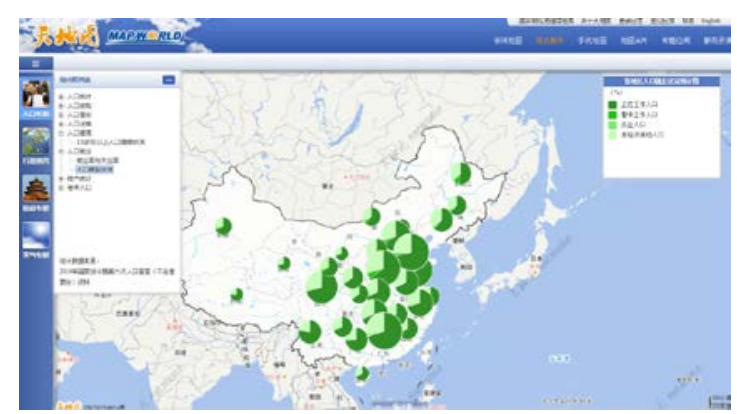

Fig 7: Population employment

\subsection{Graphic statistic method}

The analysis based on dataset and statistic units of all kinds of data can be transformed in 
to statistic graphics. The statistic graphic dataset contains number, constituent, time serie and frequency distribution. The statistic units contain district units, physical geographic units and so on. The graphics can be divided into simple graphic, complex graphic and combination graphic. The simple graphic contains bar graph and pie graph. Complex graphic expresses the interior differences and changing rule of elements.

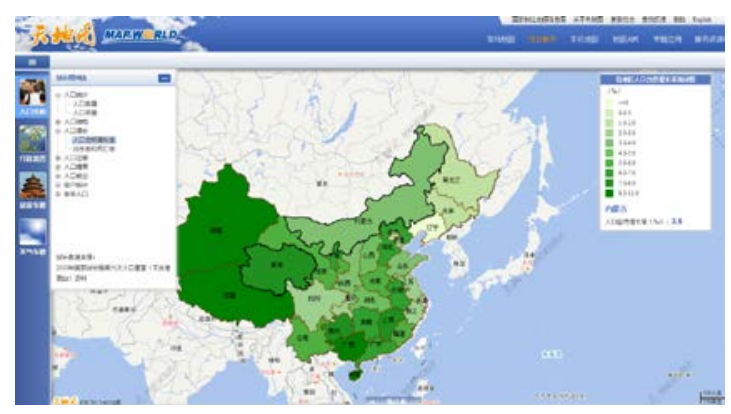

Fig: 8: The natural population growth rate

\subsection{Grading statistic method}

The number can be divided into grades and give relative color to reflect the level of a phenomenon. The principle of grade division is based on the objectives, characteristics and numbers. the grading statistic method can give full expression to the map theme and reflect the number characteristic and spatial distribution regulation rightly.

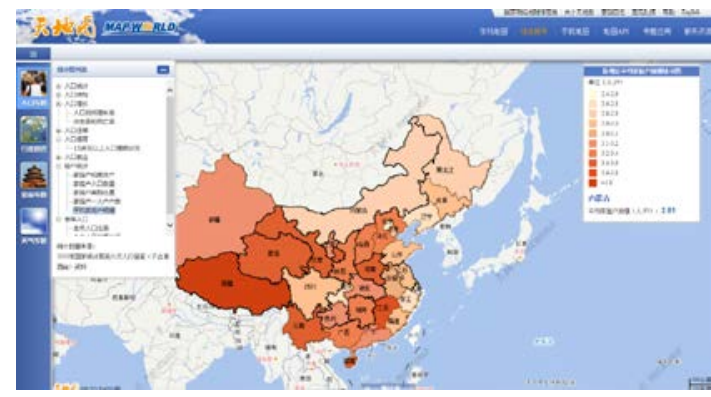

Fig: 9: The average size of household

\section{CONCLUSION}

Informationization is a necessary process in the development of disabled people affair management. And the spatial-temporal analysis and decision-making assistant system based on Mapworld is an important part of informationization. The proposed system can doing statistics and analysis of the basic information, economy, recovery and employment of the disabled people. The basic condition and changing rules can be mastered which could provide the decision-making support to the manager. The efficiency of disabled people manage department can be analyzed, which can make support to the benefit analysis. Mapworld makes all the information mentioned above more visualized and macroscopic. It takes an important role in the promotion of informationization level as well as management level of China disabled persons' federation.

\section{REFERENCES}

[1]C.G. Zheng. Social insurance of disabled people: current situation and future development[J]. Journal of Renmin University of China, 2008(1):2-9.

[2]C.L. Sun. Strategic plan and information system desigh of disabled persons' federation of Shandong province[D]. Jinan:Shandong University, 2011.

[3]W Huang, J Jiang, Q Wang. Geo-spatial framework data system in platform of geographic information service [J]. Geomatics World,2011(4):20-23.

[4]J.S Zhou. The design and implement of a web based statistical cartographic system[D]. Wuhan:Wuhan University,2005.

[5]J Huo. A research of web statistical map visual system[D].Xian:Shanxi Normal University,2008.

[6]X.L Wu, C.Y Li, X.X Zhang. The investigation of health conditions, psychological conditions and living status in handicapped [J]. Chinese Journal of Disease Control \& Prevention, 1999(4):290-292.

[7] D.R Li, J.H Huang, Z.F Shao. Design and implementation of Service oriented sharing platform framework.[J]. Geomatics and 
The International Archives of the Photogrammetry, Remote Sensing and Spatial Information Sciences, Volume XL-7/W4, 2015 2015 International Workshop on Image and Data Fusion, 21 - 23 July 2015, Kona, Hawaii, USA

Information Science of Wuhan University, 2008(9): 881-885.

[8]D.R Li, Z.F Shao, X.M Yang. The theory and practice from digital city to smart city[J]. Geospatial Information, 2011(5): 1-5. 